\section{CITAÇÃO}

Claro, P.R. (2018)

Espectroscopia Rotacional,

Rev. Ciência Elem., V6(01):005.

doi.org/10.24927/rce2018.005

\section{EDITOR}

José Ferreira Gomes,

Universidade do Porto

\section{EDITOR CONVIDADO}

Luís Vítor Duarte,

Universidade de Coimbra

\section{RECEBIDO EM}

04 de janeiro de 2018

\section{ACEITE EM}

14 de fevereiro de 2018

\section{PUBLICADO EM}

14 de março de 2018

\section{COPYRIGHT}

(C) Casa das Ciências 2018.

Este artigo é de acesso livre, distribuído sob licença Creative Commons com a designação CC-BY-NC-SA 4.0, que permite a utilização e a partilha para fins não comerciais, desde que citado o autor e a fonte original do artigo.

rce.casadasciencias.org

\title{
Espectroscopia Rotacional
}

\author{
Paulo Ribeiro Claro \\ CICECO/Universidade de Aveiro \\ prc@ua.pt
}

Designa-se por "espectroscopia rotacional" a técnica que mede a interação da radiação eletromagnética com os movimentos de rotação de um sistema molecular.

A observação de transições entre níveis quânticos rotacionais exige que o sistema em estudo tenha liberdade rotacional - tipicamente, moléculas, iões ou radicais em fase gasosa. Esta limitação não permite a aplicação generalizada da espectroscopia rotacional como técnica analítica, como no caso de outras técnicas espectroscópicas que admitem amostras em fase condensada (i.e., líquidos ou sólidos). No entanto, é uma técnica historicamente importante na determinação rigorosa de geometrias moleculares e tem ainda um contributo muito relevante em astroquímica: é através da espectroscopia rotacional que são identificadas diversas moléculas (e iões moleculares) no espaço, utilizando radiotelescópios de grande dimensão como o ALMA (Atacama Large Millimetre Array).

0 modelo mais simples para descrever as rotações moleculares é o modelo do rotor rígido diatómico: dois átomos de massa $m_{1}$ e $m_{2}$, separados por uma distância fixa R (FIGURA 1A).

Por resolução da equação de Schrödinger para este modelo, obtém-se a expressão da energia dos níveis rotacionais

$$
E_{\lrcorner}=\frac{h^{2}}{g_{\pi}^{2} I} \mathrm{~J}(\mathrm{~J}+1)
$$

Nesta expressão, J é o número quântico rotacional ( $\mathrm{U} \in \mathrm{N}_{\mathrm{o}}$, ou seja, pode tomar os valores $0,1,2,3,4, \ldots)$ e $I$ é o momento de inércia do rotor.

0 momento de inércia é dado por

$$
\mathbf{I}=\mathrm{m}_{1} \mathrm{r}_{1}^{2}+\mathrm{m}_{2} \mathrm{r}_{2}^{2}
$$

onde $r_{1}$ e $r_{2}$ são as distâncias ao centro de massa $\left(r_{1}+r_{2}=R\right)$. Esta expressão é equivalente a $I=\mu R^{2}$, sendo $\mu$ a massa reduzida do rotor, $\mu=\frac{\mathbf{m}_{1} \mathbf{m}_{2}}{\mathbf{m}_{1}+\mathbf{m}_{2}}$

A equação (1) pode então escrever-se como

$$
E_{J}=\frac{h^{2}}{B x^{2} \mu R^{2}} J(J+1)
$$


Esta forma salienta os dois fatores que afetam os níveis energia do rotor e são característicos de cada rotor: a massa e a distância entre massas. É possível agrupar estes fatores numa constante $B$, que é característica do sistema considerado. Daqui resulta uma forma simplificada da equação (3) - notar que $B$ tem unidades de energia:

$$
E_{\mathbf{J}}=\mathbf{B J}(\mathbf{J}+1)
$$

A equação (4) permite calcular facilmente os valores de energia de cada nível em função de $\mathrm{J}$, assim como a separação energética entre os diferentes níveis, representada na FIGURA 1B.
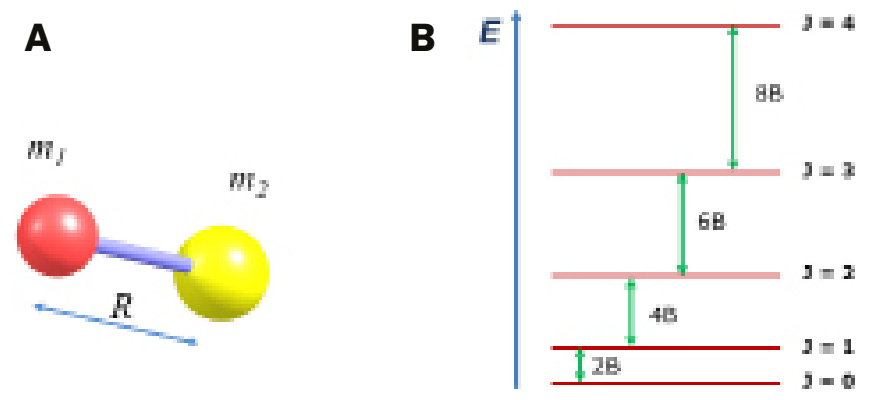

FIGURA 1. A- Rotor rígido diatómico, constituído por duas esferas de massa $m_{1}$ e $m_{2}$ separadas pela distância R. B- Esquema da distribuição dos níveis de energia rotacionais em função do número quântico J e valor da separação energética entre níveis consecutivos.

A regra de seleção para as transições rotacionais é $\Delta \mathrm{J}= \pm 1$, ou seja, apenas são observáveis transições entre níveis consecutivos. Daqui resulta que as transições observadas correspondem a $2 \mathrm{~B}, 4 \mathrm{~B}, 6 \mathrm{~B}, .$. e portanto aparecem no espectro rotacional de absorção a intervalos de valor constante, igual a 2B (FIGURA 2). Experimentalmente, a partir do valor de $B$, sendo conhecidas as massas dos átomos, é possível determinar com grande rigor 0 valor do comprimento de ligação, $R$.

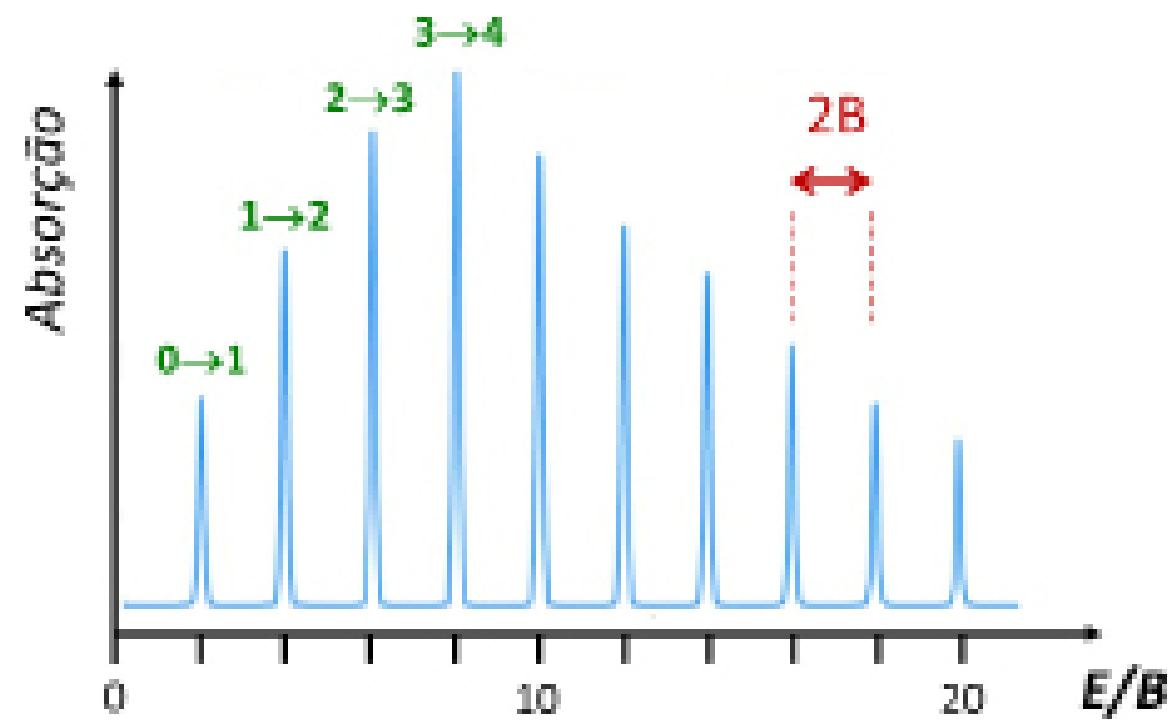

FIGURA 2. Espectro rotacional de um rotor rígido diatómico, evidenciando a separação constante (2B) entre as bandas de absorção. 
O perfil de intensidades observado na figura, com o máximo de absorção observado para a transição $\mathrm{J}=3$ para $\mathrm{J}=4$, merece uma explicação adicional. A intensidade de absorção depende do número de moléculas da amostra (população) que se encontra no nível de partida - no caso da FIGURA 2, o nível $\mathrm{J}=3$. Com exceção do nível $\mathrm{J}=0$, todos os níveis rotacionais representados na FIGURA IA são degenerados (há mais do que um nível com a mesma energia). 0 grau de degenerescência de cada nível $J$ é dado por $2 J+1$, o que significa que a linha inferior na FIGURA $1 B$ representa um nível $(\mathrm{J}=0)$, mas a linha de $\mathrm{J}=3$ representa sete níveis. Numa amostra gasosa, as moléculas distribuem-se pelos diversos níveis rotacionais disponíveis de acordo com a distribuição de população de Boltzmann, ou seja, a população é maior no nível inferior $(\mathrm{J}=0)$ e decresce exponencialmente com 0 aumento de J. No entanto, como os níveis apresentam degenerescência total crescente, numa situação em que a separação energética entre níveis é muito pequena, é possível que a totalidade da população nos sete níveis de $\mathrm{J}=3$ seja superior à população do nível único $\mathrm{J}=0$. A intensidade máxima de absorção corresponde ao valor de $\mathrm{J}$ para o qual o aumento do número de níveis degenerados ainda ultrapassa a diminuição de população nos níveis por aumento da energia.

Esta abordagem de "rotor rígido" permite interpretar os espectros rotacionais sem ter em consideração a constituição do sistema em termos de átomos e ligações químicas: na verdade, apenas interessam os momentos de inércia do sistema.

Na sua maioria, as moléculas não são lineares e possuem rotação em torno de três eixos. Estes eixos - em torno dos quais a molécula roda - são designados por eixos principais de inércia e para cada um é definido um momento de inércia, $I$, definido de forma análoga à da equação (2).

Os três momentos de inércia são designados por $I_{a}, I_{b}, I_{c}$, e os respetivos eixos $a, b, c$, sendo que, por convenção, o eixo a corresponde ao eixo de menor momento de inércia $\left(I_{a}\right)$ e o eixo $c$ corresponde ao eixo de maior momento de inércia $\left(\boldsymbol{I}_{c}\right)$. Assim, a ordem é sempre

$$
I_{c} \geq I_{b} \geq I_{a}
$$

As moléculas poliatómicas são então classificadas de acordo com os seus momentos de inércia, ao qual está associado um modelo de interpretação do respetivo espectro rotacional:

Rotor linear - com um momento de inércia nulo: $I_{c}=I_{b}, I_{a}=0$.
Rotor esférico - três momentos de inércia iguais: $I_{c}=I_{b}=I_{a}$.
Rotor simétrico - dois momentos de inércia iguais: $I_{c}=I_{b} \neq I_{a}$
Rotor simétrico - dois momentos de inércia iguais: $I_{c}=I_{b} \neq I_{a}$

No caso do rotor simétrico, a forma da molécula pode ainda ser "ao alto" (no inglês, prolate) ou "ao baixo" (no inglês, oblate, sendo que neste caso $I_{c} \neq I_{b}=I_{a}$ ). Exemplos destes dois tipos de moléculas são o clorometano e o benzeno, respetivamente. 
Os rotores reais não são rígidos, já que a ligação química é deformável. Uma das consequências deste facto é que o aumento da frequência de rotação provoca uma distorção no valor de $\mathrm{R}$ devido ao aumento da força centrífuga. Este efeito é contabilizado através da constante de distorção centrífuga, D, na definição da energia dos níveis rotacionais do rotor diatómico

$$
E_{\lrcorner}=B(J+1)-D J^{2}(J+1)^{2}
$$

$O$ valor de $D$ é baixo para ligações pouco deformáveis e elevado para ligações muito deformáveis - o que permite obter experimentalmente informação acerca da rigidez de uma ligação química.

A descrição do espectro rotacional de moléculas poliatómicas não lineares tem de incluir não apenas os diferentes momentos de inércia mas também as diferentes constantes de distorção centrífuga associadas a cada eixo de inércia - o que aumenta significativamente a complexidade do problema, que será objeto de um texto mais específico (exemplo, FIGURA 3).

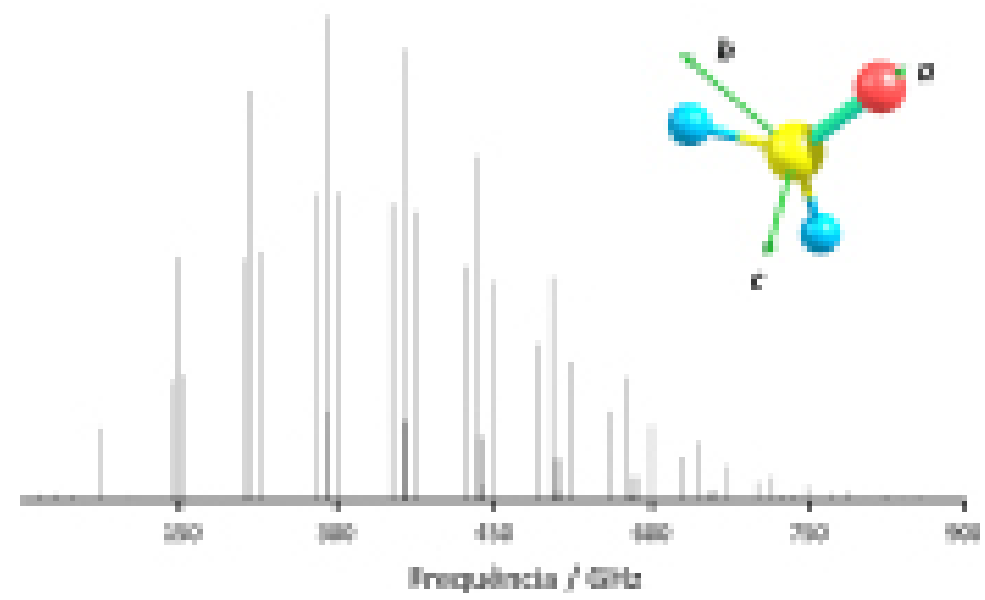

FIGURA 3. Espectro rotacional da molécula de formaldeído $\left(\mathrm{H}_{2} \mathrm{CO}\right)$, simulado com o programa PGOPHER ${ }^{1}$. Os três eixos principais de inércia estão indicados e os três momentos de inércia desta molécula são $I_{a}=1,77$, $I_{b}=13,08$ e $I_{c}=14,45$ uma. $\breve{A}^{2}$, pelo que pode ser considerada um rotor aproximadamente simétrico $\left(I_{b} \approx I_{c}\right)$.

\section{REFERÊNCIAS}

${ }^{1}$ WESTERN, C. M., PGOPHER: A program for simulating rotational, vibrational and electronic spectra, Journal of Quantitative Spectroscopy and Radiative Transfer, 186, 221-242, 2016. ${ }^{2}$ HOLLAS, J. M., High Resolution Spectroscopy, 2a Edição, Wiley VCH, 1998, ISBN: 0471974218 ${ }^{3}$ ATKINS, P. e PAULA, J., Physical Chemistry, Eighth Edition, W. H. Freeman and Company, 2006, ISBN: 0-7167-8759-8 